\section{Large intramural colonic hematoma after polypectomy}


Fig. 1 Intramural colonic hematoma.

Fig. 2 Polypectomy site with bulging mass in the upper margin.

Fig. 3 Appearance at 4 days after the polypectomy.
A 77-year-old man, who had undergone surgery 1 year previously for a colorectal carcinoma of the sigmoid colon, came to our endoscopy unit for surveillance colonoscopy. A $10-\mathrm{mm}$, pedunculated, polyp was observed at $45 \mathrm{~cm}$ from the anus. The patient was not receiving anticoagulation or antiaggregation treatment, and his platelet count and prothrombin activity were normal.

The lesion was resected using a snare and endocut (ERBE ICC 200). A few seconds later, a progressively bulging congestive mass, corresponding to a large intramural colonic hematoma, appeared below the polypectomy site and occupied almost all the colonic lumen ( $\bullet$ Fig. 1 and $\mathbf{2}$ ).

The patient was admitted for observation and showed no important decrease in hematocrit level or any symptom. At 4 days after the event, a surveillance colonoscopy showed violet-colored flat mucosa, without the mass previously seen (○ Fig. 3).

Endoscopy_UCTN_Code_CPL_1AJ_2AC

O. Nogales Rincón, I. Yepes Barreto, A. Hernando Alonso, C. González Asanza, P. Menchén Fernández-Pacheco Department of Gastroenterology. HGU Gregorio Marañón, Madrid, Spain

Bibliography

DOI $10.1055 / \mathrm{s}-2008-1077694$

Endoscopy 2009; 41: E3

(c) Georg Thieme Verlag KG Stuttgart · New York . ISSN 0013-726X

Corresponding author

\section{O. Nogales Rincón, MD}

Unidad de Endoscopias, HGU Gregorio Marañón

C. Doctor Esquerdo, 46

Madrid, 28006

Spain

Fax: +34-915-868307

oscarnogalesrincon@gmail.com 